\title{
IN VITRO INHIBITION OF PURIFIED HUMAN CARBONIC ANHYDRASE I AND II BY NOVEL FLUORENE DERIVATIVES
}

\author{
Hulya Demirhan ${ }^{1}$, Mustafa Arslan ${ }^{2}$, Mustafa Oguzhan Kaya ${ }^{3}$, Yesim Kaya ${ }^{4}$, \\ Nahit Gencer ${ }^{* *}$, Oktay Arslan ${ }^{4}$ \\ ${ }^{I}$ Department of Chemical Processing, Pamukova Vocational High School, \\ Sakarya University, Sakarya, Turkey \\ ${ }^{2}$ Department of Chemistry, Science and Art Faculty, Sakarya University, Sakarya, Turkey \\ ${ }^{3}$ Siirt University, Faculty of Arts and Sciences, Chemistry Department, 56100, Siirt, Turkey \\ ${ }^{4}$ Department of Chemistry, Science and Art Faculty, Balikesir University, Balikesir, Turkey ${ }^{2}$ \\ ngencer@balikesir.edu.tr
}

\begin{abstract}
In this study, 9-benzylidene-9H-fluorene-substituted urea (5a-p) and thiourea derivatives (5q-v) were synthesized and their inhibitory effects on the activity of human carbonic anhydrase (hCA) I and II were evaluated. hCA I and II were purified from human erythrocytes using a Sepharose 4B-L-tyrosinesulphanilamide affinity column. All the synthesized compounds inhibited the activity of the hCA I and II isoenzymes. Among the synthesized compounds, $\mathbf{5 f}$ was found to be the most active $\left(\mathrm{IC}_{50}=21.4 \mu \mathrm{M}\right)$ for inhibition of hCA I and $\mathbf{5 s}$ was the most active $\left(\mathrm{IC}_{50}=25.3 \mu \mathrm{M}\right)$ for inhibition of hCA II.
\end{abstract}

Keywords: 9-benzylidene-9H-fluorene; urea; thiourea; carbonic anhydrase; inhibition

\section{IN VITRO ИНХИБИЦИЈА НА ПРЕЧИСТЕНА ЧОВЕЧКА КАРБОНСКА АНХИДРАЗА I И II СО НОВИ ФЛУОРЕНСКИ ДЕРИВАТИ}

Во оваа студија беа синтетизирани деривати на уреа (5a-p) и тиоуреа $(\mathbf{5 q}-\mathbf{v})$ добиени со супституција на 9-безилиден-9H-флуорен и беше проценет нивниот инхибиторен ефект врз човечка карбонска анхидраза (hCA) I и II. HCA I и II беа пречистени од човечки еритроцити со употреба на афинитетната колона Sepharose 4B-L-тирозин-сулфаниламид. Сите синтетизирани соединенија ја инхибираа активноста на изоензимите на hCA I и II. Од синтетизираните соединенија, $\mathbf{5 f}$ се покажа најактивно $\left(\mathrm{IC}_{50}=21,4 \mu \mathrm{M}\right)$ за инхибиција на $\mathrm{hCA} \mathrm{I}$, додека $\mathbf{5 s}$ беше најактивно $\left(\mathrm{IC}_{50}=25,3 \mu \mathrm{M}\right)$ за инхибиција на hCA II.

Клучни зборови: 9-безилиден-9H-флуорен; уреа; тиоуреа; карбонска анхидраза; инхибиција

\section{INTRODUCTION}

Fluorene-containing compounds have unique chemical behaviours and physical properties due to the unusual geometric structure of fluorene [1]. Fluorene and its derivatives are important materials that are used in organic synthesis, the pharmaceutical and synthetic resin industries, and conductivity research [2-4]. Acetylamino-, diacetylamino-, amino- and nitro-substituted fluorene compounds increase the biological effects $[5,6]$ of an inhibitor of oncogenic tyrosine kinase [7], antimicrobial agents [8] and potent frameshift-type mutagens [9]. Many compounds containing a styryl group have been used as enzyme inhibitors. Some 9-benzylidene$9 H$-fluorene derivatives containing styryl groups may be suitable candidates for CA inhibition [10].

Due to their biological activities, substituted urea and thiourea compounds have potential as chemotherapeutic agents [11, 12], HIV protease inhibitors [13], tyrosinase inhibitors [14, 15], herbicides and antifungal agents [16]. In addition, 
recent studies have shown that different urea derivatives have dopamine hydroxylase inhibitory properties, and dopamine is a key precursor of norepinephrine [17]. Also, they are an intermediate product in various total synthesis [18]. Urea derivatives show interesting profiles for the inhibition of several human carbonic anhydrases (hCAs) such as hCA I and II (cytosolic isoforms) and hCA IX and XII (transmembrane, tumour-associated enzymes). The compounds have good inhibitory effects for all these isoforms due to the urea moiety [19].

The metalloenzyme CA (EC 4.2.1.1) catalyses a simple but critically important physiological reaction: members of the CA enzyme family catalyse hydration of $\mathrm{CO}_{2}$ to yield bicarbonate and a proton. As this reaction is involved in many physiological/pathological processes, there are widespread opportunities for the development of diverse, specific inhibitors for clinical application [20-23].

The active site of most CAs contains a zinc ion $\left(\mathrm{Zn}^{2+}\right)$ that is essential for catalysis. The CA reaction is involved in many physiological and pathological processes, including: respiration and transport of $\mathrm{CO}_{2}$ and bicarbonate between metabolizing tissues and lungs; $\mathrm{pH}$ and $\mathrm{CO}_{2}$ homeostasis; electrolyte secretion in various tissues and organs; biosynthetic reactions such as gluconeogenesis, lipogenesis and ureagenesis; bone resorption; calcification; and tumourigenicity [24-30]. Many of the CA isoenzymes involved in these processes are important therapeutic targets with the potential to be inhibited and to treat a range of disorders, including oedema, glaucoma, obesity, cancer, epilepsy and osteoporosis [31-35].

In this study, a series of 22 novel 9-benzylidene-9H-fluorene derivatives $(\mathbf{5 a}-\mathbf{v})$ containing urea/thiourea groups were synthesized and their effects on hCA I and II purified from human erythrocytes were evaluated.

\section{MATERIALS AND METHODS}

Melting points of the synthesized fluorene derivatives were determined by Yanagimoto micro-melting point apparatus and were uncorrected. IR spectra were measured on a Shimadzu Prestige21 (200 VCE) spectrometer. ${ }^{1} \mathrm{H}$ and ${ }^{13} \mathrm{C}$ NMR spectra were measured on a Varian Infinity Plus spectrometer at 300 and $75 \mathrm{~Hz}$, respectively. ${ }^{1} \mathrm{H}$ and ${ }^{13} \mathrm{C}$ chemical shifts were referenced to the internal deuterated solvent. The elemental analyses were carried out with a Leco CHNS-932 instrument. Flash column chromatography was performed using Merck silica gel 60 (230-400 mesh ASTM). All chemicals were purchased from Merck, Alfa Easer and Sigma-Aldrich.

\subsection{Synthesis \\ of 2-nitro-9-benzylidene-9-H-fluorene (3)}

2-Nitro-9-benzylidene-9H-fluorene (3) was prepared according to the literature [36]. 2-nitrofluorene $(4.22 \mathrm{~g}, 20 \mathrm{mmol})$ and $\mathrm{KOH}(3 \mathrm{~g}, 50$ mmol) were stirred in methanol for 30 minutes. Benzaldehyde (2.12 g, $20 \mathrm{mmol})$ was added and stirred overnight at room temperature. Solvent was evaporated using a rotary evaporator. The mixture was extracted with ethyl acetate $(3 \times 20 \mathrm{ml})$. The product was purified by washing with diethyl ether.

\subsection{Synthesis \\ of 2-amino-9-benzylidene-9H-fluorene $(4 a-b)$}

2-Amino-9-benzylidene-9H-fluorene was prepared according to the literature [37]. The mixture of 9-benzylidene-2-nitro-9H-fluorene $(2.99 \mathrm{~g}$, $10 \mathrm{mmol})$ and $\mathrm{SnCl}_{2}(11.3 \mathrm{~g}, 50 \mathrm{mmol})$ in THF was refluxed for $7 \mathrm{~h}$. THF was removed using a rotary evaporator, and the mixture was extracted with ethyl acetate $(3 \times 20 \mathrm{ml})$. At the end of the reaction, two products (including $E$ - and $Z$-) were obtained. The products ( $E$ - and $Z$-) were purified by column chromatography on silica gel using hexane: ethyl acetate (9:1).

\subsection{General procedure for the synthesis} of (E or Z)-1-(9-benzylidene-9H-fluoren-2-yl)-3phenylurea $(5 a-p)$

Isocyanate derivatives $(10 \mathrm{mmol})$ were added to a solution of 2-amino-9-benzylidene-9H-fluorene (E- or $Z$-) (2.68 g, $10 \mathrm{mmol})$ in toluene. The mixture was stirred at $65^{\circ} \mathrm{C}$ until precipitation. Toluene was removed using a rotary evaporator, and the product was purified by washing with ethyl ether.

\subsection{General procedure for the synthesis of (E or Z)-1-(9-benzylidene-9H-fluoren-2-yl)-3- phenylthiourea $(5 q-v)$}

Isothiocyanate derivatives $(10 \mathrm{mmol})$ were added to a solution of 2-amino-9-benzylidene-9Hfluorene ( $E$ - or $Z$-) $(2.68 \mathrm{~g}, 10 \mathrm{mmol})$ in DMF. The mixture was stirred at $40{ }^{\circ} \mathrm{C}$ until precipitation. The precipitated product was filtered and washed with a few drops of ethyl ether.

\subsection{Spectral data of novel synthesized compounds}

(Z)-1-(9-benzylidene-9H-fluoren-2-yl)-3-phenylurea (5a): Yield $79 \%$, m.p. $272-273{ }^{\circ} \mathrm{C}$; IR $(v$, $\left.\mathrm{cm}^{-1}\right): 3273(\mathrm{NH}), 3051(\mathrm{C}=\mathrm{C}-\mathrm{H}$, Aromatic C-H), $1651(\mathrm{C}=\mathrm{O}), 1551(\mathrm{O}=\mathrm{C}-\mathrm{NH}), 1222(\mathrm{C}-\mathrm{N}) ;{ }^{1} \mathrm{H}$ 
NMR (300 MHz, DMSO-d 6 , ppm): 6.95 (t, 1H, $J$ $=7.3 \mathrm{~Hz},=\mathrm{CH}), 7.23-7.92(\mathrm{~m}, 17 \mathrm{H}, \mathrm{Ar}-\mathrm{H}), 8.53(\mathrm{~s}$, $1 \mathrm{H},-\mathrm{NH}), 8.57(\mathrm{~s}, 1 \mathrm{H},-\mathrm{NH}) ;{ }^{13} \mathrm{C}$ NMR $(75 \mathrm{MHz}$, DMSO-d 6 , ppm): 92.6, 114.9, 118.8, 119.8, 120.0, $121.1,121.3,122.5,127.0,128.8,129.1,129.3$, $129.5,129.9,135.7,135.9,136.6,137.0,139.2$, 139.2, 139.7, 140.3, 153.1; Anal. Calcd. for $\mathrm{C}_{27} \mathrm{H}_{20} \mathrm{~N}_{2} \mathrm{O}: \mathrm{C}: 83.48 ; \mathrm{H}: 5.19 ; \mathrm{N}: 7.21$. Found: C: 82.92; H: 5.70; N: 7.07.

(E)-1-(9-benzylidene-9H-fluoren-2 yl)-3-phenylurea (5b): Yield $82 \%$, m.p. $277-278{ }^{\circ} \mathrm{C}$; IR $(v$, $\left.\mathrm{cm}^{-1}\right): 3290(\mathrm{NH}), 3076$ and $3024(\mathrm{C}=\mathrm{C}-\mathrm{H}$, Aromatic $\mathrm{C}-\mathrm{H}), 1637(\mathrm{C}=\mathrm{O}), 1553(\mathrm{O}=\mathrm{C}-\mathrm{NH}), 1220$ (C-N); ${ }^{1} \mathrm{H}$ NMR (300 MHz, DMSO-d 6 , ppm): 6.99-7.78 (m, 17H, =CH and $\mathrm{Ar}-\mathrm{H}), 8.08(\mathrm{~s}, 1 \mathrm{H}$, Ar-H), 8.77 (s, $1 \mathrm{H},-\mathrm{NH}), 8.82(\mathrm{~s}, 1 \mathrm{H},-\mathrm{NH}) ;{ }^{13} \mathrm{C}$ NMR (75 MHz, DMSO-d 6 , ppm): 98.2, 111.9, $119.7,119.8,120.1,120.9,121.4,122.7,126.8$, $129.0,129.4,129.5,129.8,129.9,135.8,136.2$, 136.8, 137.2, 138.9, 139.3, 139.7, 140.4, 153.5; Anal. Calcd. for $\mathrm{C}_{27} \mathrm{H}_{20} \mathrm{~N}_{2} \mathrm{O}: \mathrm{C}: 83.48 ; \mathrm{H}: 5.19 ; \mathrm{N}$ : 7.21. Found: C: $83.70 ; \mathrm{H}: 5.62$; N: 7.30.

(Z)-1-(9-benzylidene-9H-fluoren-2-yl)-3-(4-methylphenyl)urea (5c): Yield $97 \%$, m.p. $262-263{ }^{\circ} \mathrm{C}$; IR $\left(v, \mathrm{~cm}^{-1}\right): 3323(\mathrm{NH}), 3068$ and $3022(\mathrm{C}=\mathrm{C}-\mathrm{H}$, Aromatic C-H), 2924 (Aliphatic C-H), 1653 $(\mathrm{C}=\mathrm{O}), 1556(\mathrm{O}=\mathrm{C}-\mathrm{NH}), 1236(\mathrm{C}-\mathrm{N}) ;{ }^{1} \mathrm{H}$ NMR (300 MHz, DMSO-d $\left.\mathrm{d}_{6}, \mathrm{ppm}\right): 2.22\left(\mathrm{~s}, 3 \mathrm{H},-\mathrm{CH}_{3}\right)$, $7.05(\mathrm{~d}, 2 \mathrm{H}, J=8.2 \mathrm{~Hz},=\mathrm{CH}, \mathrm{Ar}-\mathrm{H}), 7.24-7.91(\mathrm{~m}$, $15 \mathrm{H}, \mathrm{Ar}-\mathrm{H}), 8.47$ (s, 1H, -NH), $8.49(\mathrm{~s}, 1 \mathrm{H},-\mathrm{NH})$; ${ }^{13} \mathrm{C}$ NMR (75 MHz, DMSO-d 6 , ppm): 21.0, 114.7, $118.9,119.8,119.8,121.1,121.3,126.9,128.91$, $129.1,129.4,129.6,129.9,129.9,131.3,135.5$, 135.9, 136.7, 137.0, 137.8, 139.2, 139.4, 139.7, 153.1; Anal. Calcd. for $\mathrm{C}_{28} \mathrm{H}_{22} \mathrm{~N}_{2} \mathrm{O}$ : C: 83.56; $\mathrm{H}$ : 5.51 ; N: 6.96. Found: C: 82.84; H: 5.26; N: 6.32 .

(E)-1-(9-benzylidene-9H-fluoren-2-yl)-3-(4-methylphenyl)urea (5d): Yield $95 \%$, m.p. $282-283{ }^{\circ} \mathrm{C}$; IR $\left(v, \mathrm{~cm}^{-1}\right): 3298(\mathrm{NH}), 3061$ and $3026(\mathrm{C}=\mathrm{C}-\mathrm{H}$, Aromatic C-H), 2910 (Aliphatic C-H), 1631 $(\mathrm{C}=\mathrm{O}), 1553(\mathrm{O}=\mathrm{C}-\mathrm{NH}), 1228(\mathrm{C}-\mathrm{N}) ;{ }^{1} \mathrm{H}$ NMR (300 MHz, DMSO-d 6 , ppm): $2.23\left(\mathrm{~s}, 3 \mathrm{H},-\mathrm{CH}_{3}\right)$, $7.00(\mathrm{t}, 1 \mathrm{H}, J=8.0 \mathrm{~Hz},=\mathrm{CH}), 7.03-7.77(\mathrm{~m}, 15 \mathrm{H}$, Ar-H), 8.07 (s, 1H, Ar-H), 8.66 (s, 1H, -NH), 8.78 $(\mathrm{s}, 1 \mathrm{H},-\mathrm{NH}) ;{ }^{13} \mathrm{C}$ NMR $(75 \mathrm{MHz}$, DMSO-d 6 , ppm): 21.0, 111.2, 119.0, 119.5, 120.2, 120.9, $124.2,126.6,128.7,129.3,129.6,129.8,129.9$, $129.9,131.4,133.3,136.2,136.3,136.9,137.8$, 140.1, 140.3, 141.6, 153.4; Anal. Calcd. for $\mathrm{C}_{28} \mathrm{H}_{22} \mathrm{~N}_{2} \mathrm{O}: \mathrm{C}: 83.56 ; \mathrm{H}: 5.51 ; \mathrm{N}: 6.96$. Found: $\mathrm{C}$ : 82.97; H: 5.09; N: 6.70.

(Z)-1-(9-benzylidene-9H-fluoren-2-yl)-3-(3-methoxyphenyl)urea (5e): Yield $92 \%$, m.p. $242-243{ }^{\circ} \mathrm{C}$; IR $\left(v, \mathrm{~cm}^{-1}\right): 3305(\mathrm{NH}), 3049$ and $3011(\mathrm{C}=\mathrm{C}-\mathrm{H}$,
Aromatic C-H), 2833 (Aliphatic C-H), 1641 $(\mathrm{C}=\mathrm{O}), 1552(\mathrm{O}=\mathrm{C}-\mathrm{NH}), 1220(\mathrm{C}-\mathrm{O}-\mathrm{C}) ;{ }^{1} \mathrm{H}$ NMR (300 MHz, DMSO-d 6 , ppm): $3.74\left(\mathrm{~s}, 3 \mathrm{H},-\mathrm{OCH}_{3}\right)$, $6.55(\mathrm{~d}, 1 \mathrm{H}, J=8.2 \mathrm{~Hz},=\mathrm{CH}), 6.90(\mathrm{~d}, 1 \mathrm{H}, J=7.9$ $\mathrm{Hz}, \mathrm{Ar}-\mathrm{H}), 7.15-7.93$ (m, 15H, Ar-H), 8.58 (s, 1H, -NH), $8.71(\mathrm{~s}, 1 \mathrm{H},-\mathrm{NH}) ;{ }^{13} \mathrm{C}$ NMR $(75 \mathrm{MHz}$, DMSO- $\left._{6}, \mathrm{ppm}\right): 55.6,104.5,111.1,114.9,117.9$, $119.8,119.9,121.1,121.3,126.9,129.0,129.4$, $129.4,129.9,129.9,130.2,135.7,135.9,136.7$, 137.1, 139.2, 139.2, 139.7, 141.5, 153.0, 160.3; Anal. Calcd. for $\mathrm{C}_{28} \mathrm{H}_{22} \mathrm{~N}_{2} \mathrm{O}_{2}$ : C: 80.36 ; H: 5.30; N: 6.69. Found: C: 80.09; H: 5.13; N: 6.21 .

(E)-1-(9-benzylidene-9H-fluoren-2-yl)-3-(3-methoxyphenyl)urea (5f): Yield $90 \%$, m.p. $241-242{ }^{\circ} \mathrm{C}$; IR $\left(v, \mathrm{~cm}^{-1}\right): 3273(\mathrm{NH}), 3068$ and $3021(\mathrm{C}=\mathrm{C}-\mathrm{H}$, Aromatic C-H), 2864 (Aliphatic C-H), $1633(\mathrm{C}=\mathrm{O})$, 1554 (O=C-NH), 1157 (C-O-C); ${ }^{1} \mathrm{H}$ NMR (300 $\left.\mathrm{MHz}, \mathrm{DMSO}-\mathrm{d}_{6}, \mathrm{ppm}\right): 3.73$ (s, $\left.3 \mathrm{H},-\mathrm{OCH}_{3}\right), 6.55(\mathrm{~d}$, $1 \mathrm{H}, J=7.9 \mathrm{~Hz},=\mathrm{CH}), 6.98-7.79(\mathrm{~m}, 15 \mathrm{H}, \mathrm{Ar}-\mathrm{H})$, 8.08 (s, 1H, Ar-H), 8.77 (s, 1H, -NH), 8.80 (s, 1H, -NH); ${ }^{13} \mathrm{C}$ NMR $\left(75 \mathrm{MHz}, \mathrm{DMSO}-\mathrm{d}_{6}, \mathrm{ppm}\right): 55.6$, $104.7,108.0,111.3,111.4,119.7,120.2,120.9$, $124.2,126.6,128.7,129.0,129.3,129.6,129.6$, $129.8,130.3,133.4,136.3,136.4,136.9,139.9$, 140.4, 141.6, 153.3, 160.4; Anal. Calcd. for $\mathrm{C}_{28} \mathrm{H}_{22} \mathrm{~N}_{2} \mathrm{O}_{2}$ : C: 80.36; H: 5.30; N: 6.69. Found: C: 80.05; H: 5.17; N: 6.32.

(Z)-1-(9-benzylidene-9H-fluoren-2-yl)-3-(4-flourophenyl)urea (5g): Yield $85 \%$, m.p. $267-268{ }^{\circ} \mathrm{C}$; IR $\left(v, \mathrm{~cm}^{-1}\right): 3261(\mathrm{NH}), 3053$ and $3016(\mathrm{C}=\mathrm{C}-\mathrm{H}$, Aromatic C-H), $1649(\mathrm{C}=\mathrm{O}), 1546(\mathrm{O}=\mathrm{C}-\mathrm{NH})$, 1217 (C-N); ${ }^{1} \mathrm{H}$ NMR (300 MHz, DMSO-d 6 , ppm): 7.13 (t, $1 \mathrm{H}, J=8.9 \mathrm{~Hz},=\mathrm{CH}), 7.26-7.93(\mathrm{~m}, 16 \mathrm{H}$, $\mathrm{Ar}-\mathrm{H}), 8.57$ (s, $1 \mathrm{H},-\mathrm{NH}), 8.64(\mathrm{~s}, 1 \mathrm{H},-\mathrm{NH}) ;{ }^{13} \mathrm{C}$ NMR (75 MHz, DMSO-d 6 , ppm): 114.9, 115.8, $116.1,119.8,119.9,120.5,120.6,121.1,121.3$, $126.9,129.0,129.4,129.9,135.7,135.9,136.7$, 137.0, 139.2, 139.3, 139.7, 153.1, 156.4, 159.5; Anal. Calcd. for $\mathrm{C}_{27} \mathrm{H}_{19} \mathrm{FN}_{2} \mathrm{O}$ : C: 79.79 ; $\mathrm{H}$ : 4.71; N: 6.89. Found: C: 79.14; H: 4.53; N: 6.95.

(E)-1-(9-benzylidene-9H-fluoren-2-yl)-3-(4-flourophenyl)urea (5h): Yield $78 \%$, m.p. $279-280{ }^{\circ} \mathrm{C}$; IR $\left(v, \mathrm{~cm}^{-1}\right): 3280(\mathrm{NH}), 3051$ and $3018(\mathrm{C}=\mathrm{C}-\mathrm{H}$, Aromatic C-H), $1633(\mathrm{C}=\mathrm{O}), 1557(\mathrm{O}=\mathrm{C}-\mathrm{NH})$, 1211(C-N); ${ }^{1} \mathrm{H}$ NMR (300 MHz, DMSO-d 6 , ppm): $7.08(\mathrm{t}, 1 \mathrm{H}, J=8.0 \mathrm{~Hz},=\mathrm{CH}), 7.16-7.81(\mathrm{~m}, 15 \mathrm{H}$, Ar-H), 8.12 (s, 1H, Ar-H), 8.84 (s, 1H, -NH), 8.85 (s, $1 \mathrm{H},-\mathrm{NH}) ;{ }^{13} \mathrm{C}$ NMR $(75 \mathrm{MHz}$, DMSO-d 6 , ppm): 111.4, 115.8, 116.1, 119.6, 120.2, 120.7, $120.8,120.9,124.2,128.7,129.0,129.3,129.6$, $129.8,133.4,136.3,136.3,136.7,136.9,139.9$, 140.4, 141.6, 153.4; Anal. Calcd. for $\mathrm{C}_{27} \mathrm{H}_{19} \mathrm{FN}_{2} \mathrm{O}$ : C: 79.79; H: 4.71; N: 6.89. Found: C: 79.21; H: $4.51 ; \mathrm{N}: 6.92$. 
(Z)-1-(9-benzylidene-9H-fluoren-2-yl)-3-(4-chlorophenyl)urea (5i): Yield $72 \%$, m.p. $244-245{ }^{\circ} \mathrm{C}$; IR $\left(v, \mathrm{~cm}^{-1}\right): 3280(\mathrm{NH}), 3049$ and $3019(\mathrm{C}=\mathrm{C}-\mathrm{H}$, Aromatic C-H), $1639(\mathrm{C}=\mathrm{O}), 1547(\mathrm{O}=\mathrm{C}-\mathrm{NH})$, $1224(\mathrm{C}-\mathrm{N}) ;{ }^{1} \mathrm{H}$ NMR $\left(300 \mathrm{MHz}, \mathrm{DMSO}-\mathrm{d}_{6}, \mathrm{ppm}\right)$ : 7.27-7.92 $(\mathrm{m}, 17 \mathrm{H},=\mathrm{CH}$ and $\mathrm{Ar}-\mathrm{H}), 8.58(\mathrm{~s}, 1 \mathrm{H},-$ $\mathrm{NH}), 8.71(\mathrm{~s}, 1 \mathrm{H},-\mathrm{NH}) ;{ }^{13} \mathrm{C}$ NMR $(75 \mathrm{MHz}$, DMSO-d $_{6}, \quad$ ppm): $115.1,119.8,120.1,120.4$, $120.4,121.1,121.3,126.0,127.0,129.1,129.3$, $129.4,129.9,130.0,135.8,135.9,136.6,137.0$, 139.1, 139.2, 139.3, 139.7, 153.0; Anal. Calcd. for $\mathrm{C}_{27} \mathrm{H}_{19} \mathrm{ClN}_{2} \mathrm{O}$ : C: $76.68 ; \mathrm{H}: 4.53$; N: 6.62. Found: C: $75.81 ; \mathrm{H}: 4.02 ; \mathrm{N}: 6.38$.

(E)-1-(9-benzylidene-9H-fluoren-2-yl)-3-(4-chlorophenyl)urea (5j): Yield $75 \%$, m.p. $259-260{ }^{\circ} \mathrm{C}$; IR $\left(v, \mathrm{~cm}^{-1}\right): 3292(\mathrm{NH}), 3057$ and $3022(\mathrm{C}=\mathrm{C}-\mathrm{H}$, Aromatic C-H), $1637(\mathrm{C}=\mathrm{O}), 1548(\mathrm{O}=\mathrm{C}-\mathrm{NH})$,

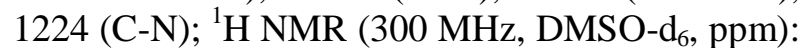
$7.05(\mathrm{t}, 1 \mathrm{H}, J=7.6 \mathrm{~Hz},=\mathrm{CH}), 7.30-7.78(\mathrm{~m}, 15 \mathrm{H}$, Ar-H), 8.55 (s, 1H, Ar-H), 8.86 (s, 1H, -NH), 8.92 $(\mathrm{s}, 1 \mathrm{H},-\mathrm{NH}) ;{ }^{13} \mathrm{C}$ NMR $\left(75 \mathrm{MHz}, \mathrm{DMSO}_{6}\right.$, ppm): 111.5, 119.8, 120.2, 120.4, 120.5, 120.9, $124.3,126.1,128.7,129.0,129.3,129.4,129.6$, $129.8,133.5,136.3,136.4,136.9,139.4,139.7$, 140.4, 141.5, 153.3; Anal. Calcd. for $\mathrm{C}_{27} \mathrm{H}_{19} \mathrm{ClN}_{2} \mathrm{O}$ : C: $76.68 ; \mathrm{H}: 4.53 ; \mathrm{N}: 6.62$. Found: C: $75.95 ; \mathrm{H}: 4.17$; N: 6.34 .

(Z)-1-(9-benzylidene-9H-fluoren-2-yl)-3-(3-chlorophenyl)urea (5k): Yield $72 \%$, m.p. $222-223{ }^{\circ} \mathrm{C}$; IR $\left(v, \mathrm{~cm}^{-1}\right): 3261(\mathrm{NH}), 3068$ and $3034(\mathrm{C}=\mathrm{C}-\mathrm{H}$, Aromatic C-H), $1643(\mathrm{C}=\mathrm{O}), 1548(\mathrm{O}=\mathrm{C}-\mathrm{NH})$, 1213 (C-N); ${ }^{1} \mathrm{H}$ NMR (300 MHz, DMSO-d 6 , ppm): $6.99(\mathrm{~d}, 1 \mathrm{H}, J=8.0 \mathrm{~Hz},=\mathrm{CH}), 7.21-7.90(\mathrm{~m}, 16 \mathrm{H}$, $\mathrm{Ar}-\mathrm{H}), 8.62(\mathrm{~s}, 1 \mathrm{H},-\mathrm{NH}), 8.78(\mathrm{~s}, 1 \mathrm{H},-\mathrm{NH}) ;{ }^{13} \mathrm{C}$ NMR $\left(75 \mathrm{MHz}, \mathrm{DMSO}_{-} \mathrm{d}_{6}, \mathrm{ppm}\right): 115.2,117.3$, $118.2,119.8,120.2,121.1,121.3,122.1,127.0$, $128.9,129.0,129.4,129.7,129.9,131.1,133.9$, 135.9, 136.1, 136.7, 137.1, 138.9, 139.1, 139.7, 141.9, 152.9; Anal. Calcd. for $\mathrm{C}_{27} \mathrm{H}_{19} \mathrm{ClN}_{2} \mathrm{O}$ : C: 76.68; H: 4.53; N: 6.62. Found: C: 75.92; H: 4.37; $\mathrm{N}: 6.20$.

(E)-1-(9-benzylidene-9H-fluoren-2-yl)-3-(3-chlorophenyl)urea (5l): Yield $73 \%$, m.p. $240-241{ }^{\circ} \mathrm{C}$; IR $\left(v, \mathrm{~cm}^{-1}\right): 3271(\mathrm{NH}), 3072$ and $3020(\mathrm{C}=\mathrm{C}-\mathrm{H}$, Aromatic C-H), $1635(\mathrm{C}=\mathrm{O}), 1551(\mathrm{O}=\mathrm{C}-\mathrm{NH})$, $1220(\mathrm{C}-\mathrm{N}) ;{ }^{1} \mathrm{H}$ NMR $\left(300 \mathrm{MHz}, \mathrm{DMSO}-\mathrm{d}_{6}, \mathrm{ppm}\right)$ : $7.01(\mathrm{t}, 1 \mathrm{H}, J=7.8 \mathrm{~Hz},=\mathrm{CH}), 7.26-7.78(\mathrm{~m}, 15 \mathrm{H}$, Ar-H), 8.09 (s, 1H, Ar-H), 8.88 (s, 1H, -NH), 8.97 $(\mathrm{s}, 1 \mathrm{H},-\mathrm{NH}) ;{ }^{13} \mathrm{C}$ NMR $\left(75 \mathrm{MHz}\right.$, DMSO-d $\mathrm{d}_{6}$, ppm): 111.6, 117.4, 118.3, 119.9, 120.2, 120.9, $122.2,124.3,126.7,128.7,129.0,129.3,129.6$, $129.8,131.1,133.6,133.9,136.2,136.4,136.9$, 139.6, 140.4, 141.5, 141.9, 153.2; Anal. Calcd. for $\mathrm{C}_{27} \mathrm{H}_{19} \mathrm{ClN}_{2} \mathrm{O}$ : C: 76.68 ; H: 4.53; N: 6.62. Found: C: $76.08 ; \mathrm{H}: 4.65 ; \mathrm{N}: 6.26$.
(Z)-1-(9-benzylidene-9H-fluoren-2-yl)-3-(3,4-dichlorophenyl)urea (5m): Yield 79\%, m.p. 248$249^{\circ} \mathrm{C}$; IR $\left(v, \mathrm{~cm}^{-1}\right): 3288(\mathrm{NH}), 3059$ and 3026 $(\mathrm{C}=\mathrm{C}-\mathrm{H}$, Aromatic C-H $), 1633(\mathrm{C}=\mathrm{O}), 1548(\mathrm{O}=\mathrm{C}-$ $\mathrm{NH}), 1228(\mathrm{C}-\mathrm{N}) ;{ }^{1} \mathrm{H}$ NMR (300 MHz, DMSO-d 6 , ppm): 7.30-7.93 (m, 16H, $=\mathrm{CH}$ and $\mathrm{Ar}-\mathrm{H}), 8.71(\mathrm{~s}$, $1 \mathrm{H},-\mathrm{NH}), 8.92(\mathrm{~s}, 1 \mathrm{H},-\mathrm{NH}) ;{ }^{13} \mathrm{C}$ NMR $(75 \mathrm{MHz}$, DMSO-d $\left._{6}, \quad \mathrm{ppm}\right): 115.3,119.0,119.8,120.0$, $120.3,121.0,121.3,123.8,127.1,128.9,129.0$, $129.4,129.6,129.9,131.2,131.7,135.9,136.1$, 136.6, 137.1, 138.8, 139.1, 139.7, 140.6, 152.9; Anal. Calcd. for $\mathrm{C}_{27} \mathrm{H}_{18} \mathrm{Cl}_{2} \mathrm{~N}_{2} \mathrm{O}$ : C: 70.91; H: 3.97; $\mathrm{N}: 6.13$. Found: C: 69.95; H: 3.39; N: 5.87.

(E)-1-(9-benzylidene-9H-fluoren-2-yl)-3-(3,4-dichlorophenyl)urea (5n): Yield 78\%, m.p. 273$274^{\circ} \mathrm{C}$; IR $\left(v, \mathrm{~cm}^{-1}\right): 3278(\mathrm{NH}), 3074$ and 3024 $(\mathrm{C}=\mathrm{C}-\mathrm{H}$, Aromatic C-H $), 1639(\mathrm{C}=\mathrm{O}), 1547(\mathrm{O}=\mathrm{C}-$ $\mathrm{NH}), 1222(\mathrm{C}-\mathrm{N}) ;{ }^{1} \mathrm{H}$ NMR (300 MHz, DMSO-d $\mathrm{d}_{6}$, ppm): $7.01(\mathrm{t}, 1 \mathrm{H}, J=7.9 \mathrm{~Hz},=\mathrm{C}), 7.26-7.78(\mathrm{~m}$, 13H, Ar-H), 7.92 (s, 1H, Ar-H), 8.08 (s, 1H, Ar-H), 8.93 (s, 1H, -NH), 9.06 (s, 1H, -NH); ${ }^{13} \mathrm{C}$ NMR(75 MHz, DMSO-d $\left.\mathrm{d}_{6}, \mathrm{ppm}\right): 111.7,119.1,119.9,120.0$, $120.2,120.9,123.9,124.2,126.7,128.8,129.0$, $129.3,129.6,129.8,131.2,131.8,133.7,136.2$, 136.4, 136.9, 139.4, 140.4, 140.6, 141.5, 153.1; Anal. Calcd. for $\mathrm{C}_{27} \mathrm{H}_{18} \mathrm{Cl}_{2} \mathrm{~N}_{2} \mathrm{O}$ : C: 70.91; H: 3.97; $\mathrm{N}: 6.13$. Found: C: 70.13; H: 3.46; N: .95 .

(Z)-1-(9-benzylidene-9H-fluoren-2-yl)-3-(4-nitrophenyl)urea (5o): Yield $91 \%$, m.p. $287-288^{\circ} \mathrm{C}$; IR $\left(v, \mathrm{~cm}^{-1}\right): 3329(\mathrm{NH}), 3055$ and $3022(\mathrm{C}=\mathrm{C}-\mathrm{H}$, Aromatic C-H), $1666(\mathrm{C}=\mathrm{O}), 1549(\mathrm{O}=\mathrm{C}-\mathrm{NH})$, $1496(\mathrm{O}-\mathrm{N}-\mathrm{O}), 1240(\mathrm{C}-\mathrm{N})$; ${ }^{1} \mathrm{H}$ NMR $(300 \mathrm{MHz}$, DMSO-d $\left._{6}, \mathrm{ppm}\right):$ 7.26-7.93 (m, 15H, Ar-H), 8.17 (d, 2H, $J=7.6 \mathrm{~Hz}$ Ar-H), 8.83 (s, 1H, -NH), 9.35 (s, 1H, -NH); ${ }^{13} \mathrm{C}$ NMR(75 MHz, DMSO-d 6 , ppm): $115.3,118.1,119.8,119.9,120.3,121.3,125.9$, $127.1,129.1,129.3,129.4,129.9,129.9,135.8$, 136.2, 136.6, 137.0, 138.6, 139.0, 139.7, 141.6, 147.0, 152.5; Anal. Calcd. for $\mathrm{C}_{27} \mathrm{H}_{19} \mathrm{~N}_{3} \mathrm{O}_{3}$ : C: 74.81 ; H: 4.42; N: 9.69. Found: C: 74.59; H: 4.05; N: 10.06.

(E)-1-(9-benzylidene-9H-fluoren-2-yl)-3-(4-nitrophenyl)urea (5p): Yield $90 \%$, m.p. $282-283^{\circ} \mathrm{C}$; IR $\left(v, \mathrm{~cm}^{-1}\right): 3284(\mathrm{NH}), 3057$ and $3028(\mathrm{C}=\mathrm{C}-\mathrm{H}$, Aromatic C-H), $1670(\mathrm{C}=\mathrm{O}), 1548(\mathrm{O}=\mathrm{C}-\mathrm{NH})$, 1495 (O-N-O), 1228 (C-N); ${ }^{1} \mathrm{H}$ NMR (300 MHz, DMSO-d $6, \mathrm{ppm}): 7.08\left(\mathrm{t}, 1 \mathrm{H}, J=7.9 \mathrm{~Hz},=\mathrm{CH}_{2}\right.$ ), $7.22-7.83(\mathrm{~m}, 14 \mathrm{H}, \mathrm{Ar}-\mathrm{H}), 8.21(\mathrm{~d}, 2 \mathrm{H}, J=8.0 \mathrm{~Hz}$, $\mathrm{Ar}-\mathrm{H}), 9.11(\mathrm{~s}, 1 \mathrm{H},-\mathrm{NH}), 9.58(\mathrm{~s}, 1 \mathrm{H},-\mathrm{NH}) ;{ }^{13} \mathrm{C}$ NMR (75 MHz, DMSO-d $\left.\mathrm{d}_{6}, \mathrm{ppm}\right): 111.8,118.2$, $120.0,120.3,121.0,124.3,125.9,126.8,129.1$, $129.3,129.6,129.8,129.9,134.0,136.2,136.4$, 136.9, 139.2, 140.4, 141.4, 141.7, 147.1, 152.8; Anal. Calcd. for $\mathrm{C}_{27} \mathrm{H}_{19} \mathrm{~N}_{3} \mathrm{O}_{3}$ : C: $74.81 ; \mathrm{H}: 4.42 ; \mathrm{N}$ : 9.69. Found: C: 74.50; H: 4.13; N: 9.98. 
(Z)-1-(9-benzylidene-9H-fluoren-2-yl)-3-phenylthiourea (5q): Yield $92 \%$, m.p. $148-149^{\circ} \mathrm{C}$; IR ( $v$, $\left.\mathrm{cm}^{-1}\right): 3217(\mathrm{NH}), 3051$ and $3018(\mathrm{C}=\mathrm{C}-\mathrm{H}$, Aromatic C-H), $1539(\mathrm{~S}=\mathrm{C}-\mathrm{N}-\mathrm{H}), 1255(\mathrm{C}-\mathrm{N}) ;{ }^{1} \mathrm{H}$ NMR (300 MHz, DMSO-d $\left.\mathrm{d}_{6}, \mathrm{ppm}\right): 7.25$ (t, 1H, $J=$ $7.9 \mathrm{~Hz},=\mathrm{CH}), 7.43-7.94(\mathrm{~m}, 17 \mathrm{H}, \mathrm{Ar}-\mathrm{H}), 9.73$ (s, $1 \mathrm{H},-\mathrm{NH}), 9.82(\mathrm{~s}, 1 \mathrm{H},-\mathrm{NH}) ;{ }^{13} \mathrm{C}$ NMR $(75 \mathrm{MHz}$, DMSO-d $_{6}, \quad$ ppm): $120.2,120.4,120.8,121.4$, $124.4,124.6,125.1,127.5,129.0,129.4,129.8$, $130.0,135.6,136.5,137.9,138.8,140.0,140.2$, 180.0; Anal. Calcd. for $\mathrm{C}_{27} \mathrm{H}_{20} \mathrm{~N}_{2} \mathrm{~S}$ : C: $80.17 ; \mathrm{H}$ : 4.98; N: 6.92; S: 7.93. Found: C: 80.31; H: 4.66; N: 6.57; S: 8.09 .

(E)-1-(9-benzylidene-9H-fluoren-2-yl)-3-phenylthiourea (5r): Yield $98 \%$, m.p. $151-152^{\circ} \mathrm{C}$; IR ( $v$, $\left.\mathrm{cm}^{-1}\right): 3221(\mathrm{NH}), 3039$ and $3019(\mathrm{C}=\mathrm{C}-\mathrm{H}$, Aromatic C-H), $1524(\mathrm{~S}=\mathrm{C}-\mathrm{N}-\mathrm{H}), 1253(\mathrm{C}-\mathrm{N}) ;{ }^{1} \mathrm{H}$ NMR (300 MHz, DMSO-d $\left.\mathrm{d}_{6}, \mathrm{ppm}\right):$ 7.07-7.18 (m, $2 \mathrm{H},=\mathrm{CH}$ and $\mathrm{Ar}-\mathrm{H}), 7.34-7.85(\mathrm{~m}, 14 \mathrm{H}, \mathrm{Ar}-\mathrm{H})$, 8.03 (s, 1H, Ar-H), 9.85 (s, 1H, -NH), 9.88 (s, 1H, $-\mathrm{NH}) ;{ }^{13} \mathrm{C}$ NMR (75 MHz, DMSO-d $\left.\mathrm{d}_{6}, \mathrm{ppm}\right): 117.8$, $120.2,120.50120 .7,124.3,124.4,124.6,125.2$, $125.7,127.2,129.2,129.7,135.9,136.0,136.6$, $136.8,138.7,139.4,139.9,140.1,141.2,180.0$, 180.6; Anal. Calcd. for $\mathrm{C}_{27} \mathrm{H}_{20} \mathrm{~N}_{2} \mathrm{~S}$ : C: $80.17 ; \mathrm{H}$ : 4.98; N: 6.92; S: 7.93. Found: C: 80.28; H: 4.39; $\mathrm{N}: 6.40 ; \mathrm{S}: 7.98$.

(Z)-1-(9-benzylidene-9H-fluoren-2-yl)-3-(4-methylphenyl)thiourea (5s): Yield 95\%, m.p. 116$117^{\circ} \mathrm{C}$; IR $\left(v, \mathrm{~cm}^{-1}\right): 3167(\mathrm{NH}), 3049$ and 3024 $(\mathrm{C}=\mathrm{C}-\mathrm{H}$, Aromatic C-H), 2920 (Aliphatic C-H), $1516(\mathrm{~S}=\mathrm{C}-\mathrm{NH}), 1255(\mathrm{C}-\mathrm{N}) ;{ }^{1} \mathrm{H}$ NMR $(300 \mathrm{MHz}$, DMSO-d 6 , ppm): 2.29 (s, 3H, $\left.-\mathrm{CH}_{3}\right), 7.15$ (t, $1 \mathrm{H}, J$ $=8.2 \mathrm{~Hz},=\mathrm{CH}), 7.28-7.97(\mathrm{~m}, 16 \mathrm{H}, \mathrm{Ar}-\mathrm{H}), 9.64$ (s, 1H, -NH), $9.73(\mathrm{~s}, 1 \mathrm{H},-\mathrm{NH}) ;{ }^{13} \mathrm{C}$ NMR $(75$ MHz, DMSO-d $\left.\mathrm{d}_{6}, \mathrm{ppm}\right): 21.2,120.2,120.5,120.8$, $121.4,124.7,124.9,125.2,127.5,129.1,129.4$, $129.5,129.7,129.8,130.0,134.4,135.6,136.5$, $137.5,137.9,138.8,138.8,139.9,180.1$; Anal. Calcd. for $\mathrm{C}_{28} \mathrm{H}_{22} \mathrm{~N}_{2} \mathrm{~S}$ : C: 80.35; H: 5.30; N: 6.69; S: 7.66. Found: C: 80.02; H: 5.14; N: 6.31; S: 7.74.

(E)-1-(9-benzylidene-9H-fluoren-2-yl)-3-(4-methylphenyl)thiourea (5t): Yield 94\%, m.p. 116$117^{\circ} \mathrm{C}$; IR $\left(v, \mathrm{~cm}^{-1}\right): 3207(\mathrm{NH}), 3024$ and 3024 $(\mathrm{C}=\mathrm{C}-\mathrm{H}$, Aromatic C-H), 2918 (Aliphatic C-H), $1518(\mathrm{~S}=\mathrm{C}-\mathrm{NH}), 1253(\mathrm{C}-\mathrm{N}) ;{ }^{1} \mathrm{H}$ NMR $(300 \mathrm{MHz}$, DMSO-d $6, \mathrm{ppm}): 2.27$ (s, 3H, $\left.-\mathrm{CH}_{3}\right), 7.08$ (t, $1 \mathrm{H}, J$ $=8.0 \mathrm{~Hz},=\mathrm{CH}), 7.14-7.72(\mathrm{~m}, 15 \mathrm{H}, \mathrm{Ar}-\mathrm{H}), 8.02$ $(\mathrm{s}, 1 \mathrm{H}, \operatorname{Ar}-\mathrm{H}), 9.79(\mathrm{~s}, 1 \mathrm{H},-\mathrm{NH}), 9.95(\mathrm{~s}, 1 \mathrm{H},-$ $\mathrm{NH}) ;{ }^{13} \mathrm{C}$ NMR $\left(75 \mathrm{MHz}, \mathrm{DMSO}-\mathrm{d}_{6}, \mathrm{ppm}\right): 21.2$, $119.7,120.1,120.6,121.8,125.0,125.4,126.9$, $128.9,129.2,129.6,129.7,130.0,130.2,133.9$, 135.6, 136.7, 138.0, 138.7, 139.4, 139.5, 139.8, 140.2, 180.8; Anal. Calcd. for $\mathrm{C}_{28} \mathrm{H}_{22} \mathrm{~N}_{2} \mathrm{~S}$ : C:
80.35; H: 5.30; N: 6.69; S: 7.66. Found: C: 80.19; H: 5.11; N: 6.24; S: 7.71 .

(Z)-1-(9-benzylidene-9H-fluoren-2-yl)-3-(4-methoxyphenyl)thiourea (5u): Yield 89\%, m.p. 136$137^{\circ} \mathrm{C}$; IR $\left(v, \mathrm{~cm}^{-1}\right): 3157(\mathrm{NH}), 3049(\mathrm{C}=\mathrm{C}-\mathrm{H}$, Aromatic C-H), 2955 (Aliphatic C-H), 1510 ( $\mathrm{S}=\mathrm{C}-$ $\mathrm{NH}), 1240\left(\mathrm{Ar}-\mathrm{O}-\mathrm{CH}_{3}\right) ;{ }^{1} \mathrm{H}$ NMR $(300 \mathrm{MHz}$, DMSO-d $\left.\mathrm{d}_{6}, \mathrm{ppm}\right): 3.75\left(\mathrm{~s}, 3 \mathrm{H},-\mathrm{OCH}_{3}\right), 6.92(\mathrm{~d}, 2 \mathrm{H}$, $J=8.4 \mathrm{~Hz}, \mathrm{Ar}-\mathrm{H}), 7.28-7.96(\mathrm{~m}, 15 \mathrm{H},=\mathrm{CH}$ and Ar-H), 9.57 (s, 1H, -NH), 9.68 (s, $1 \mathrm{H},-\mathrm{NH}) ;{ }^{13} \mathrm{C}$ NMR(75 MHz, DMSO-d $\left.\mathrm{d}_{6}, \mathrm{ppm}\right): 55.9,114.3$, $120.2,120.4,120.7,121.4,125.2,126.7,127.5$, $129.0,129.1,129.4,129.8,130.0,132.9,135.7$, $136.5,137.9,138.8,138.9,140.0,157.2,180.3$; Anal. Calcd. for $\mathrm{C}_{28} \mathrm{H}_{22} \mathrm{~N}_{2} \mathrm{OS}$ : C: 77.39; H: 5.10; $\mathrm{N}: 6.45 ; \mathrm{S}: 7.38$. Found: C: 77.53; H: 4.92; N: 6.20; S:7.47.

(E)-1-(9-benzylidene-9H-fluoren-2-yl)-3-(4-methoxyphenyl)thiourea (5v): Yield 90\%, m.p. 147$148^{\circ} \mathrm{C}$; IR $\left(v, \mathrm{~cm}^{-1}\right): 3159(\mathrm{NH}), 3048(\mathrm{C}=\mathrm{C}-\mathrm{H}$, Aromatic C-H), 2911 (Aliphatic C-H), 1511 (S=C$\mathrm{NH}), 1240\left(\mathrm{Ar}-\mathrm{O}-\mathrm{CH}_{3}\right) ;{ }^{1} \mathrm{H}$ NMR $(300 \mathrm{MHz}$, DMSO-d 6 , ppm): 3.73 (s, 3H, $\left.-\mathrm{OCH}_{3}\right), 6.93(\mathrm{~d}, 2 \mathrm{H}$, $J=8.2 \mathrm{~Hz}, \mathrm{Ar}-\mathrm{H}), 7.18(\mathrm{t}, 1 \mathrm{H}, J=7.9 \mathrm{~Hz},=\mathrm{CH})$, 7.32-7.90 (m, 13H, Ar-H), 8.05 (s, 1H, Ar-H), 9.69 (s, 1H, -NH), 9.74 (s, $1 \mathrm{H},-\mathrm{NH}) ;{ }^{13} \mathrm{C} \mathrm{NMR}(75 \mathrm{MHz}$, DMSO- $\left.\mathrm{d}_{6}, \mathrm{ppm}\right): 55.9,114.4,115.8,117.8,120.5$, $120.7,124.3,125.6,126.6,126.9,128.0,129.1$, $129.4,129.8,132.9,135.8,136.1,136.6,136.9$, 139.6, 139.9, 141.3, 157.3, 180.9; Anal. Calcd. For $\mathrm{C}_{28} \mathrm{H}_{22} \mathrm{~N}_{2} \mathrm{OS}$ : C: 77.39; H: 5.10; N: 6.45; S: 7.38 . Found: C: 77.65; H: 4.87; N: 6.18; S: 7.49.

\section{CA ENZYME ASSAY}

\subsection{Preparation and purification of haemolysate from red blood cells}

Blood samples $(25 \mathrm{ml})$ were taken from healthy human volunteers. They were anticoagulated with acid-citrate-dextrose, centrifuged at $5000 \mathrm{rpm}$ for $20 \mathrm{~min}$ at $4{ }^{\circ} \mathrm{C}$ and the supernatant was removed. The packed erythrocytes were washed three times with $0.9 \% \mathrm{NaCl}$ and then haemolysed in cold water. The ghosts and any intact cells were removed by centrifugation at $15000 \mathrm{rpm}$ for $25 \mathrm{~min}$ at $4{ }^{\circ} \mathrm{C}$, and the $\mathrm{pH}$ of the haemolysate was adjusted to $\mathrm{pH} 8.5$ with solid Tris-base. The haemolysate $(25 \mathrm{ml})$ was applied to an affinity column containing -sulfonamide- Ltyrosine -Sepharose-4B [38] equilibrated with 25 $\mathrm{mM}$ Tris- $\mathrm{HCl} / 0.1 \mathrm{M} \mathrm{Na}_{2} \mathrm{SO}_{4}(\mathrm{pH}$ 8.5). The affinity gel was washed with $50 \mathrm{ml}$ of $25 \mathrm{mM}$ Tris- $\mathrm{HCl} / 22$ $\mathrm{mM} \mathrm{Na} \mathrm{SO}_{4}(\mathrm{pH}$ 8.5). The human CA (hCA) 
isozymes were then eluted with $0.1 \mathrm{M} \mathrm{NaCl} / 25$ $\mathrm{mM} \mathrm{Na} 2 \mathrm{HPO}_{4}$ (pH 6.3) and $0.1 \mathrm{M} \mathrm{CH}_{3} \mathrm{COONa} / 0.5$ $\mathrm{M} \mathrm{NaClO}_{4}$ (pH 5.6), which recovered hCA I and II respectively. Fractions of $3 \mathrm{ml}$ were collected and their absorbance measured at $280 \mathrm{~nm}$.

\subsection{In vitro inhibition studies}

CA activity was measured by the Maren method, which is based on determination of the time required for the $\mathrm{pH}$ to decrease from 10.0 to 7.4 due to $\mathrm{CO}_{2}$ hydration [39]. The assay solution was $0.5 \mathrm{M} \mathrm{Na}_{2} \mathrm{CO}_{3} / 0.1 \mathrm{M} \mathrm{NaHCO}_{3}$ (pH 10.0) and phenol red was added as the $\mathrm{pH}$ indicator. $\mathrm{CO}_{2^{-}}$ hydratase activity (enzyme units (EU)) was calculated by using the equation $\left(t_{0}-t_{\mathrm{c}}\right) / t_{\mathrm{c}}$ where $t_{0}$ and $t_{\mathrm{c}}$ are the times for $\mathrm{pH}$ change of the non-enzymatic and the enzymatic reactions, respectively.
For the inhibition studies of synthesized compounds, different concentrations of these compounds were added to the enzyme. Activity percentage values of CA for each concentration of each compound were determined by regression analysis using Microsoft Office 2000 Excel. CA enzyme activity without urea solution was deemed to be $100 \%$.

\section{RESULTS AND DISCUSSION}

2-Nitro-9-benzylidene-9H-fluorene (3) was synthesized from 2-nitrofluorene (1) and the compound was reduced with tin (II) chloride in THF. The $E$ - and $Z$-isomers of 2-nitro-9-benzylidene$9 H$-fluorene (4a-b) were reacted with isocyanates/isothiocyanates to get the final products $(\mathbf{5 a}-\mathbf{v})$ at high yields. The synthetic procedures are depicted in Scheme 1.

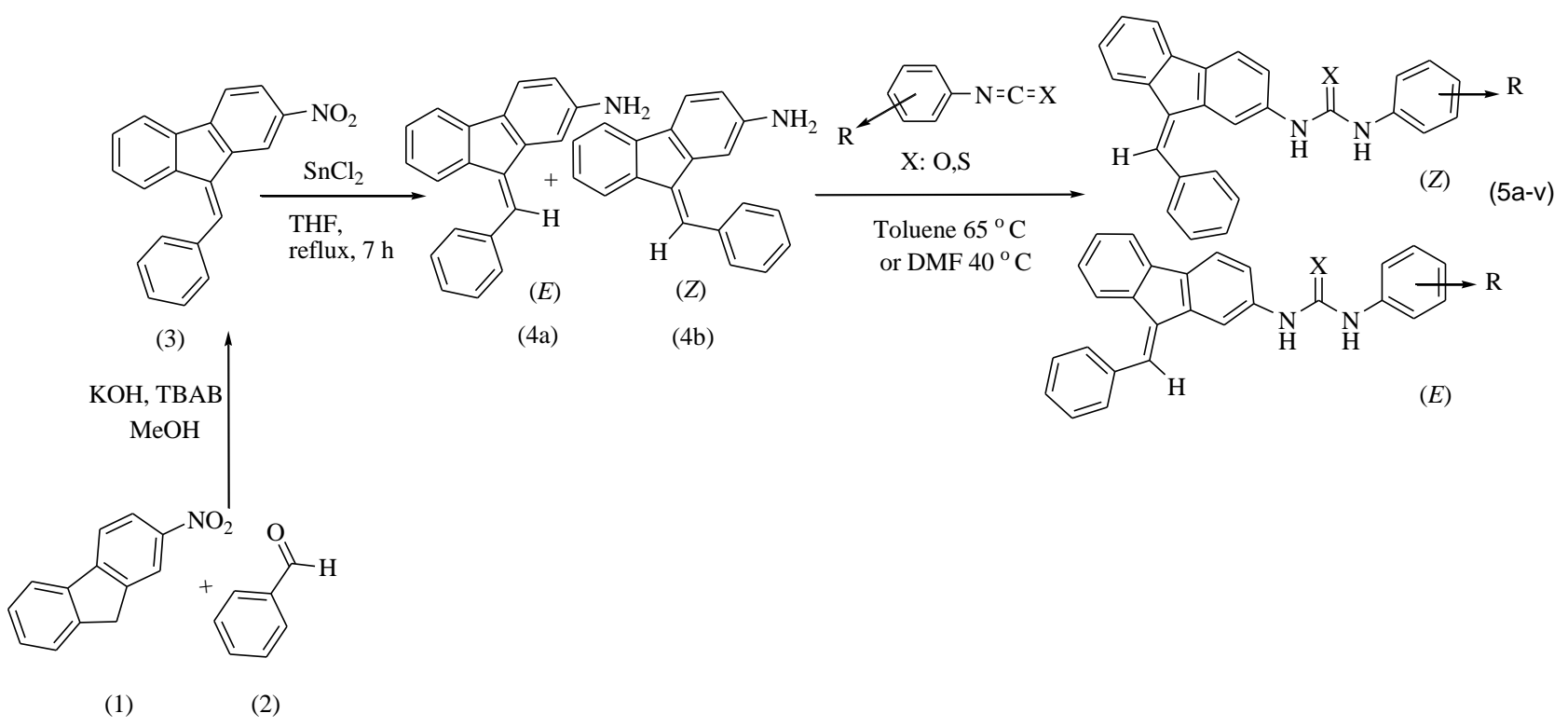

\begin{tabular}{|c|c|c|c|c|c|c|c|c|}
\hline \multirow{4}{*}{$\begin{array}{l}\mathrm{X} \\
\mathrm{R} \\
\text { Conf. }\end{array}$} & $5 a$ & $5 b$ & $5 c$ & $5 d$ & $5 e$ & $5 f$ & $5 \mathrm{~g}$ & $5 \mathrm{~h}$ \\
\hline & $\mathrm{O}$ & $\mathrm{O}$ & $\mathrm{O}$ & $\mathrm{O}$ & $\mathrm{O}$ & $\mathrm{O}$ & $\mathrm{O}$ & $\mathrm{O}$ \\
\hline & $\mathrm{H}$ & $\mathrm{H}$ & 4- $-\mathrm{CH}_{3}$ & 4- $-\mathrm{CH}_{3}$ & 3-OMe & 3-OMe & 4-F & $4-F$ \\
\hline & $Z-$ & $E-$ & $Z-$ & $E-$ & Z- & $E-$ & $Z-$ & $E-$ \\
\hline \multirow{4}{*}{$\begin{array}{l}\mathrm{X} \\
\mathrm{R} \\
\text { Conf. }\end{array}$} & $5 \mathbf{i}$ & $5 \mathrm{j}$ & $5 k$ & 51 & $5 \mathrm{~m}$ & $5 n$ & 50 & $5 p$ \\
\hline & $\mathrm{O}$ & $\mathrm{O}$ & $\mathrm{O}$ & $\mathrm{O}$ & $\mathrm{O}$ & $\mathrm{O}$ & $\mathrm{O}$ & $\mathrm{O}$ \\
\hline & 4-Cl & $4-\mathrm{Cl}$ & $3-\mathrm{Cl}$ & $3-\mathrm{Cl}$ & 3,4-di-Cl & 3,4-di-Cl & $4-\mathrm{NO}_{2}$ & $4-\mathrm{NO}_{2}$ \\
\hline & $Z-$ & $E-$ & $Z-$ & $E-$ & $Z-$ & $E-$ & Z- & $E-$ \\
\hline \multirow{4}{*}{$\begin{array}{l}\mathrm{X} \\
\mathrm{R} \\
\text { Conf. }\end{array}$} & $5 q$ & $5 r$ & $5 \mathrm{~s}$ & $5 \mathrm{t}$ & $5 u$ & $5 v$ & & \\
\hline & $\mathrm{S}$ & $\mathrm{S}$ & $\mathrm{S}$ & $\mathrm{S}$ & $\mathrm{S}$ & $\mathrm{S}$ & & \\
\hline & $\mathrm{H}$ & $\mathrm{H}$ & 4- $\mathrm{CH}_{3}$ & 4- $-\mathrm{CH}_{3}$ & 4-OMe & 4-OMe & & \\
\hline & $Z-$ & $E-$ & $Z-$ & $E-$ & Z- & $E-$ & & \\
\hline
\end{tabular}

Scheme 1. Synthesis of ( $E$ or $Z$ )-1-(9-benzylidene-9H-fluoren-2-yl)-3-phenylurea/thiourea derivatives 
The synthesized compounds were characterized by ${ }^{1} \mathrm{H}$ NMR, ${ }^{13} \mathrm{C}$ NMR, IR and elemental analysis. From the ${ }^{1} \mathrm{H}$ NMR spectra, the resonance due to the hydrogen attached to the amide nitrogen was between 8.50 and $10.00 \mathrm{ppm}$. The signals for aromatic and vinylic protons were between 7.00 and $8.50 \mathrm{ppm}$. From the ${ }^{13} \mathrm{C}$ NMR spectra, carbon atoms of urea carbonyl were observed between 182 and $150 \mathrm{ppm}$. In the infrared spectra of compounds $\mathbf{5 a}-$ $\mathbf{v}$, it was possible to observe the absorptions between 3250 and $3450 \mathrm{~cm}^{-1}$ relating to N-H stretching and absorptions at $1650-1750 \mathrm{~cm}^{-1}$ from the urea carbonyl moiety stretching. Furthermore, absorptions between 1180 and $1280 \mathrm{~cm}^{-1}$ indicated C$\mathrm{N}$ stretching.

Table 1
To evaluate the hCA I and II inhibitory effects, all compounds were subjected to hCA I and II inhibition assays with $\mathrm{CO}_{2}$ as a substrate. The results showed that these compounds $(\mathbf{5 a}-\mathbf{v})$ inhibited the CA enzyme activity. The $\mathrm{IC}_{50}$ values of 5a-v analogues for hCA I and II are summarized in Table 1. The $\mathrm{IC}_{50}$ values were between 21.4 and $211.4 \mu \mathrm{M}$ for hCA I enzyme activity and between 25.3 and $82.4 \mu \mathrm{M}$ for hCA II. Among the compounds, $5 \mathbf{5 f}\left(\mathrm{IC}_{50}=21.4 \mu \mathrm{M}\right)$ was found to be the most active compound for hCA I inhibitory activity and $\mathbf{5 s}\left(\mathrm{IC}_{50}=25.3 \mu \mathrm{M}\right)$ showed the highest hCA II inhibitory activity.

The $I C_{50}$ values of (E or Z)-1-(9-benzylidene-9H-fluoren-2-yl)-3-phenylurea/thiourea derivatives

\begin{tabular}{ccccc|ccccc}
\hline $\begin{array}{c}\text { Comp./ } \\
\text { Conf. }\end{array}$ & $\mathrm{X}$ & $\mathrm{R}$ & $\begin{array}{c}\text { hCA I } \\
(\mu \mathrm{M})\end{array}$ & $\begin{array}{c}\text { hCA II } \\
(\mu \mathrm{M})\end{array}$ & $\begin{array}{c}\text { Comp./ } \\
\text { Conf. }\end{array}$ & $\mathrm{X}$ & $\mathrm{R}$ & $\begin{array}{c}\text { hCA I } \\
(\mu \mathrm{M})\end{array}$ & $\begin{array}{c}\text { hCA II } \\
(\mu \mathrm{M})\end{array}$ \\
\hline $5 \mathrm{a} / Z$ & $\mathrm{O}$ & $\mathrm{H}$ & 43.9 & 56.9 & $5 \mathrm{l} / E$ & $\mathrm{O}$ & $3-\mathrm{Cl}$ & 52.7 & 63.8 \\
$5 \mathrm{~b} / E$ & $\mathrm{O}$ & $\mathrm{H}$ & 32.75 & 64.98 & $5 \mathrm{~m} / Z$ & $\mathrm{O}$ & $3,4-\mathrm{di}-\mathrm{Cl}$ & 67.0 & 38.3 \\
$5 \mathrm{c} / Z$ & $\mathrm{O}$ & $4-\mathrm{CH}_{3}$ & 66.9 & 29.2 & $5 \mathrm{n} / E$ & $\mathrm{O}$ & $3,4-\mathrm{di}-\mathrm{Cl}$ & 72.9 & 51.5 \\
$5 \mathrm{~d} / E$ & $\mathrm{O}$ & $4-\mathrm{CH}_{3}$ & 74.6 & 25.6 & $5 \mathrm{o} / Z$ & $\mathrm{O}$ & $4-\mathrm{NO}_{2}$ & 23.1 & 35.9 \\
$5 \mathrm{e} / Z$ & $\mathrm{O}$ & $3-\mathrm{OCH}_{3}$ & 32.0 & 40.55 & $5 \mathrm{p} / E$ & $\mathrm{O}$ & $4-\mathrm{NO}_{2}$ & 37.4 & 28.6 \\
$5 \mathrm{f} / E$ & $\mathrm{O}$ & $3-\mathrm{OCH}_{3}$ & 21.4 & 62.8 & $5 \mathrm{q} / Z$ & $\mathrm{~S}$ & $\mathrm{H}$ & 157.3 & 29.2 \\
$5 \mathrm{~g} / Z$ & $\mathrm{O}$ & $4-\mathrm{F}$ & 73.5 & 63.0 & $5 \mathrm{r} / E$ & $\mathrm{~S}$ & $\mathrm{H}$ & 58.0 & 41.4 \\
$5 \mathrm{~h} / E$ & $\mathrm{O}$ & $4-\mathrm{F}$ & 50.44 & 51.3 & $5 \mathrm{~s} / Z$ & $\mathrm{~S}$ & $4-\mathrm{CH}_{3}$ & 35.01 & 25.3 \\
$5 \mathrm{i} / Z$ & $\mathrm{O}$ & $4-\mathrm{Cl}$ & 66.5 & 36.8 & $5 \mathrm{t} / E$ & $\mathrm{~S}$ & $4-\mathrm{CH}_{3}$ & 62.7 & 43.9 \\
$5 \mathrm{j} / E$ & $\mathrm{O}$ & $4-\mathrm{Cl}$ & 211.4 & 55.1 & $5 \mathrm{u} / \mathrm{Z}$ & $\mathrm{S}$ & $4-\mathrm{OCH}_{3}$ & 24.6 & 68.6 \\
$5 \mathrm{k} / Z$ & $\mathrm{O}$ & $3-\mathrm{Cl}$ & 64.8 & 37.9 & $5 \mathrm{v} / E$ & $\mathrm{~S}$ & $4-\mathrm{OCH}_{3}$ & 23.0 & 82.4 \\
\hline \hline
\end{tabular}

The following conclusions should be noted regarding the CA inhibitory data of Table 1 .

(i) The slow cytosolic isoform hCA I was inhibited by the 9-benzylidene-9H-fluorene-substituted diaryl urea and thiourea derivatives with inhibition constants in the range 21.4-211.4 $\mu \mathrm{M}$. The best hCA I inhibitor among the novel compounds was $\mathbf{5 f}$. $E$-isomers of urea and thiourea compounds, which do not have any group at the phenyl ring, showed a higher inhibitory effect than $Z$-isomers for hCA I. A methoxy group at the phenyl ring had a greater inhibitory effect for hCA I than for hCA II, while a methyl group at the phenyl ring had a higher inhibitory effect for hCA II than for hCA I.

(ii) The second off-target isoform (hCA II), which is in fact the physiologically dominant cytosolic isozyme, was also inhibited by all the compounds with inhibition constants in the range 25.3$82.4 \mu \mathrm{M}$. The best hCA II inhibitor among the novel compounds was $\mathbf{5 s}$. Z-isomers of the synthesized compounds were generally more effective in the inhibition of hCA II. Both $Z$ - and $E$-isomers of the synthesized compounds containing $-\mathrm{NO}_{2}$ groups at the phenyl ring had a higher inhibitory effect. A chlorine atom at the meta-position of the phenyl ring exhibited a greater inhibitory effect than at the para-position.

In conclusion, we have evaluated the effect of urea $(\mathbf{5 a}-\mathbf{p})$ and thiourea $(\mathbf{5 q}-\mathbf{v})$ derivatives on hCA I and II purified from human erythrocytes and structure-activity relationships were examined. The synthesized compounds inhibited the hCA I and II isoenzyme activities. The urea derivatives as inhibitor were bound within the enzyme active site $[19,40]$. We assume that the synthesized fluorenecontaining urea/thiourea derivatives inhibited hCA I and II in the same way or that the fluorenyl moiety interacted with the hydrophobic pocket of the enzyme.

In summary, enzyme inhibition is an important issue for drug design and biochemical applications [41-45]. Our results suggest that these novel compounds are likely to be adopted as candidates 
for the treatment of glaucoma and that they should be further evaluated in in vivo studies.

Acknowledgements: This work was supported by the Research Fund of the Sakarya University. Project Number: 2012-02-04-043.

\section{REFERENCES}

[1] M. S. Novikov, A. F. Khlebnikov, M. A. Egarmin, M. V. Shevchenko, V. A. Khlebnikov, R. R. Kostikov, D. Vidovic, Regioselectivity of the 1,3-Dipolar Cycloaddition of Fluorinated Fluoren-9-iminium Ylides to Heteroelement-Containing Dipolarophiles: Experimental and Quantum-Chemical Study, Russian J. Org. Chem., 42, 1800-1812 (2006).

[2] V. Lukes, D. Vegh, P. Hrdlovic, M. Stefko, K. Matuszna, V. Laurinc, Synthesis, theoretical characterisation and spectra of thiophene-fluorene $\pi$-conjugated derivatives, Synthetic Metals, 148, 179-186 (2005).

[3] S. L. Tao, Z. K. Peng, X. H. Zhang, P. F. Wang, C. S. Lee, S. T. Lee, Highly Efficient Non-Doped Blue Organic Light-Emitting Diodes Based on Fluorene Derivatives with High Thermal Stability, Advanced Functional Mat., 15, 1716-1721 (2005).

[4] G. Hsu, J. R. Kiefer, D. Burnouf, O. J. Becherel, R. P. P. Fuchs, L. S. Beese, Observing Translesion Synthesis of an Aromatic Amine DNA Adduct by a High-fidelity DNA Polymerase, J. Biol. Chem., 279, 50280-50285 (2004).

[5] S. Schulman, Fluorene Derivatives for Cancer Research, J. Org. Chem., 14, 382-387 (1949).

[6] L. A. Pinck, On the Carcinogenesis of 2-Substituted Fluorenes, Comments and Communications, 109, 209 (1949).

[7] PATENT: S. Ahmed, P. C. Gambacorti, P. G. Goekjian, D. Gueyrard, R. H. Gunby, F. Popowycz, L. Scapozza, C. Schneider, A. Zambon, US20110112110 A1; (2011).

[8] P. Marinova, M. Marinov, Y. Feodorova, M. Kazakova, D. Georgiev, E. Trendafilova, P. Penchev, V. Sarafian, N. Stoyanov, Synthesis, antimicrobial and in vitro antiproliferative activity of 4'-bromo-(9'-fluorene)-spiro-5-(2,4dithiohydantoin) against tumor cells, Scientific Works: University of Ruse "Angel Kanchev" 52, 33-37 (2013).

[9] B. Beije, L. Möller, 2-nitrofluorene and related compounds: prevalence and biological effects, Mutation Research/Reviews in Genetic Toxicology, 196, 177-209 (1988).

[10] C. Jing, L. Yang, F. Junxiang, 9-Benzylidene-9Hfluorene Derivatives Linked to Monoaza-15-crown-5: Synthesis and Metal Ion Sensing, Chin. J. Chem., 30, 1571-1574 (2012).

[11] M. Houimel, J-P. Mach, I. Corthésy-Theulaz, B. Corthésy, I. Fisch, New inhibitors of Helicobacter pylori urease holoenzyme selected from phage-displayed peptide libraries, Eur. J. Biochem., 262, 774-780 (1999).

[12] I. J. M. Rosenstein, J. M. T. Hamilton-Miller, D. M. Musher, Inhibitors of urease as chemotherapeutic agents, Crit. Rev. Microbiol., 11, 1-12 (1984).

[13] H. Dulude, R. Salvador, G. Gallant, Synthesis and antiHIV activity of new urea and nitrosourea derivatives of diamino acids, Bioorg. Med. Chem, 3, 151-160 (1995).
[14] N. Gencer, D. Demir, F. Sonmez, M. Kucukislamoglu, New saccharin derivatives as tyrosinase inhibitors, Bioorg. Med. Chem., 20, 2811-2821 (2012).

[15] A. R. Nixha, M. Arslan, Y. Atalay, N. Gencer, A. Ergun, O. Arslan, Synthesis and theoretical calculations of carbazole substituted chalcone urea derivatives and studies their polyphenol oxidase enzyme activity, J. Enzyme Inhib. Med. Chem., 28, 808-815 (2013).

[16] G. Madhava, K. Venkata Subbaiah, R. Sreenivasulu, C. Naga Raju, Synthesis of novel urea and thiourea derivatives of diphenylphosphoramidate and their antimicrobial activity Der Pharmacia Lettre, 4, 1194-1201 (2012).

[17] M. Avalos, R. Babiano, P. Cintas, M. M. Chavero, F. J. Higes, J. L. Jimenez, J. C. Palacios, G. Silvero, Reactions of 2-amino-2-thiazolines with isocyanates and isothiocyanates. Chemical and computational studies on the regioselectivity, adduct rearrangement, and mechanistic pathways, J. Org. Chem., 65, 8882-8892 (2000).

[18] M. D'hooghe, N. De Kimpe, Synthetic approaches towards 2-iminothiazolidines: an overview, Tetrahedron, 62, 513-535 (2006).

[19] F. Pacchiano, F. Carta, P. C. McDonald, Y. Lou, D. Vullo, A. Scozzafava, S. Dedhar, C. T. Supuran, Ureidosubstituted benzenesulfonamides potently inhibit carbonic anhydrase IX and show antimetastatic activity in a model of breast cancer metastasis, J. Med. Chem., 54 1896-1902 (2011).

[20] C. T. Supuran, Carbonic anhydrases: novel therapeutic applications for inhibitors and activators, Nat. Rev. Drug Disc., 7, 168-181 (2008).

[21] A. Thiry, J. M. Dogné, B. Masereel, C. T. Supuran, Targeting tumor associated carbonic anhydrase IX in cancertherapy, Trends Pharmacol. Sci., 27, 566-573 (2006).

[22] J. M. McKiernan, R. Buttyan, N. H. Bander, M. D. Stifelman, A. E. Katz, M. W. Chen, C. A. Olsson, I. S. Sawczuk, Expression of the tumor-associated gene MN: A potential biomarker for human renal cell carcinoma, Cancer Res., 57, 2362-2365 (1997).

[23] A. Scozzafava, A. Mastrolorenzo, C.T. Supuran, Carbonic anhydrase inhibitors and activators and their use in therapy, Expert Opin. Ther. Pat., 16, 1627-1664 (2006).

[24] C. T. Supuran, A. Scozzafava, A. Casini, Carbonic anhydrase inhibitors, Med. Res. Rev., 23, 146-189 (2003).

[25] K. S. Smith, J. G. Ferry, Prokaryotic carbonic anhydrases, FEMS Microbiol. Rev., 24, 335-366 (2000).

[26] T. Stams, D. W. Christianson, The Carbonic Anhydrases: New Horizons, Birkhauser Verlag, Boston, 2000, pp. 159-174.

[27] S. Pastorekova, S. Parkkila, J. Pastorek, C. T. Supuran, Carbonic anhydrases: Current state of the art, therapeutic applications and future prospects, J. Enzyme. Inhib. Med. Chem., 19, 199-229 (2004).

[28] I. Nishimori, T. Minakuchi, S. Onishi, D. Vullo, A. Cecchi, A. Scozzafava, C. T. Supuran, Carbonic anhydrase inhibitors: Cloning, characterization, and inhibition studies of the cytosolic isozyme III with sulphonamides, Bioorg. Med. Chem., 15, 7229-7236 (2007).

[29] I. Nishimori, D. Vullo, A. Innocenti, A. Scozzafava, A. Mastrolorenzo, C. T. Supuran, Carbonic anhydrase in- 
hibitors. The mitochondrial isozyme VB as a new target for sulfonamide and sulfamate inhibitors, J. Med. Chem., 48, 7860-7866 (2005).

[30] D. Vullo, J. Voipio, A. Innocenti, C. Rivera, H. Ranki, A. Scozzafava, K. Kaila, C. T. Supuran, Carbonic anhydrase inhibitors. Inhibition of the human cytosolic isozyme VII with aromatic and heterocyclic sulphonamides, Bioorg. Med. Chem. Lett., 15, 971-976 (2005).

[31] C. T. Supuran, A. Scozzafava, J. Conway, Carbonic Anhydrase: Its Inhibitors and Activators, CRC Press, Boca Raton, 2004, pp. 25-43.

[32] D. Vullo, M. Franchi, E. Gallori, J. Pastorek, A. Scozzafava, S. Pastorekova, C. T. Supuran, Carbonic anhydrase inhibitors: Inhibition of the tumor-associated isozyme IX with aromatic and heterocyclic sulphonamides, Bioorg. Med. Chem. Lett. 13, 1005-1009 (2003).

[33] D. Vullo, A. Innocenti, I. Nishimori, J. Pastorek, A. Scozzafava, S. Pastoreková, C. T. Supuran, Carbonic anhydrase inhibitors. Inhibition of the transmembrane isozyme XII with sulfonamides-a new target for the design of antitumor and antiglaucoma drugs, Bioorg. Med. Chem., Lett. 15, 963-969 (2005).

[34] J. Lehtonen, B. Shen, M. Vihinen, A. Casini, A. Scozzafava, C. T. Supuran, A. K. Parkkila, J. Saarnio, A. J. Kivela, A. Waheed, W. S. Sly, S. Parkkila, Characterization of CA XIII, a novel member of the carbonic anhydrase isozyme family, J. Biol. Chem., 279, 2719-2727 (2004).

[35] I. Nishimori, D. Vullo, A. Innocenti, A. Scozzafava, A. Mastrolorenzo, C.T. Supuran, Carbonic anhydrase inhibitors: Inhibition of the transmembrane isozyme XIV with sulphonamides, Bioorg. Med. Chem. Lett., 15, 3828-3833 (2005).

[36] H. Demirhan, M. Arslan, M. Zengin, M. Kucukislamoglu, A Comparative Study in Oxidative Free Radical Reactions between 9-Benzylidene-9H-fluorene Derivatives and $\beta$-Dicarbonyl Compounds in the Presence of $\mathrm{Mn}(\mathrm{OAc})_{3}$ and CAN, Lett. In Org. Chem., 8, 488-494 (2011).
[37] R. Annunziata, V. Molteni, L. Raimondi, Synthesis and structural assignment of 2,4'-disubstituted benzylidenefluorenes and 4'-substituted benzylidene-1-azafluorenes, Magn. Reson. Chem., 36, 520-528 (1998).

[38] O. Arslan, B. Nalbantoglu, N. Demir, H. Ozdemir, O. I. Kufrevioglu, A new method for the purification of carbonic anhyrase isozymes by affinity chromatography, Turk. J. Med. Sci., 26, 163-166 (1996).

[39] T. H. Maren, A simplified micromethod for the determination of carbonic anhydrase and its inhibitors, $J$. Pharm. Exp. Ther., 130, 2629-2634 (1960).

[40] F. Pacchiano, M. Aggarwal, B. S. Avvaru, A. H. Robbins, A. Scozzafava, R. McKenna, C. T. Supuran, Selective hydrophobic pocket binding observed within the carbonic anhydrase II active site accommodate different 4-substituted-ureido-benzenesulfonamides and correlate to inhibitor potency, Chem. Commun., 46, 8371-8373 (2010).

[41] K. Erol, N. Gencer, M. Arslan, O. Arslan, Purification, characterization, and investigation of in vitro inhibition by metals of paraoxonase from different sheep breeds, Artif. Cells Nanomed. Biotechnol., 41, 125-130 (2013).

[42] N. Gencer, A. Ergun, D. Demir, In vitro effects of some anabolic compounds on erythrocyte carbonic anhydrase I and II, J. Enzyme Inhib. Med. Chem., 27, 208-210 (2012).

[43] N. Berber, M. Arslan, E. Yavuz, C. Bilen, N. Gencer, Synthesis and Evaluation of New Phthalazine Urea and Thiourea Derivatives as Carbonic Anhydrase Inhibitors, J. Chem., 2013, 1-8 (2013).

[44] D. Demir, N. Gencer, A. Er, Purification and characterization of prophenoloxidase from Galleria mellonella L. Artif. Cells Nanomed. Biotechnol., 40, 391-395 (2012).

[45] B. Gokce, N. Gencer, O. Arslan, S. A. Turkoglu, M. Alper, F. Kockar, Evaluation of in vitro effects of some analgesic drugs on erythrocyte and recombinant carbonic anhydrase I and II, J. Enzyme Inhib. Med. Chem., 7, 37-42 (2012). 
